\title{
СОВРЕМЕННАЯ ПРОБЛЕМАТИКА В ПОСТРОЕНИИ СИСТЕМЫ УПРАВЛЕНИЯ ИННОВАЦИЯМИ В ОПОРНЫХ ВУЗАХ РЕГИОНОВ
}

\author{
(c) 2019 Франк Евгений Владимирович \\ аспирант \\ Самарский государственный технический университет, Россия, Самара \\ E-mail: Evgeny-frank@mail.ru
}

В данной работе исследованы ключевые проблемы и направления развития в построении системы управления инновациями опорных ВУЗов регионов. Рассмотрение данного вопроса актуально в контексте реализации национальных проектов. В этой связи цель работы - определение современной проблематики в построении системы управления инновациями в опорных ВУЗах регионов.

Ключевые слова: инновационный менеджент, опорный ВУЗ, национальные проекты, бизнес-инкубатор, бизнес-акселератор, стартап.

Повышение конкурентоспособности российских компаний на внешнем и внутреннем рынке играет важную роль в стабилизации экономики и формирования потенциала к её дальнейшему росту. Во многом этот процесс определяют инновации.

Для выполнения столь масштабной задачи необходимо подключение высококлассных специалистов, обладающих соответствующими компетенциями, которых будет достаточно для формирования возможностей инновационного развития компаний. В приоритете у опорных высших учебных заведений (опорных ВУЗов) стоит выпуск на рынок труда именно таких специалистов. Особо значимым это становится для региональных ВУЗов, которые обеспечивают сотрудниками организации, ставящие своей целью повышение конкурентоспособности как на внутреннем, так и на внешнем рынках.

Повышение инновационной активности бизнеса стало целью государственной программы экономического развития и инновационной экономики. Обеспечение высокого качества российского образования в соответствии с меняющимися запросами населения, а также обеспечение его конкурентоспособности на мировом рынке является целью государственной программы развития образования. Связующим звеном в реализации этих программ может стать управление инновациями в опорных ВУЗах регионов.

Актуальным данный вопрос становится и в разрезе выполнения национальных проектов «Образование», «Наука», «Производительность труда и поддержка занятости», а также «Цифро- вая экономика Российской Федерации». Опорные ВУЗы регионов могут дать импульс к их реализации путём выпуска на рынок высококвалифицированных специалистов, способных работать в условиях цифровой экономики, а также их поддержке в формировании инновационных предприятий. В этой связи целью работы становится определение современной проблематики в построении системы управления инновациями в опорных ВУЗах регионов.

Современная практика показывает, что страны, которые сделали ставку на наукоёмкую отрасль вышли в авангард мировой экономики. Основой наукоёмких отраслей же стал человеческий капитал [1]. Он формировался, в том числе, за счёт инновационной деятельности университетов.

Немаловажную роль в этом процессе сыграло именно грамотное управление инновациями. Само понятие управления инновациями является весьма новым для российских ВУЗов.

В современной трактовке под инновациями понимается конечный результат создания, освоения и внедрения новшества, удовлетворяющего конкретные потребности, с целью получения научно-технического, экономического или социального эффекта.

Управление инновациями является процессом, который заключается в перманентном совершенствовании различных сторон деятельности организации, в данном случае ВУЗа, путём создания, освоения и внедрения новшеств.

Для успешного развития системы управления инновациями необходимо развивать сочетания научной и предпринимательской со- 
ставляющих. Опорные ВУЗы регионов должны аккумулировать научный потенциал, транслируя и распространяя его на предпринимательские инициативы, а также воплощая в форме малых инновационных предприятий.

Проведение исследований и экспериментов, научный поиск, целью которых является получение новых знаний, а также расширение уже имеющихся, послужили основополагающим базисом деятельности университета.

Научно-исследовательская деятельность стала драйвером развития фундаментальной и прикладной науки. В научных лабораториях и центрах совершаются открытия, проводятся эксперименты, подтверждаются или отвергаются гипотезы, устанавливаются закономерности, осуществляются обобщения, проектируются и конструируются новые изобретения.

Однако на первый план в Российской Федерации сейчас вышел поиск возможностей по осуществлению интеграции научных достижений ВУЗов в российскую экономику, применение в практике деятельности организаций, а также их коммерциализация и развитие малых форм предпринимательства.

Основная проблема, наметившаяся в данный момент в Российской Федерации, заключается в том, что внутри ВУЗов отсутствует сформированная эффективная система управления инновациями. Работа должна строиться последовательно и структурировано.

Корпоративная стратегия и инновационный процесс должны быть согласованы. Инновационная стратегия описывается в контексте влияния на достижение стратегических целей с помощью инноваций. Следующим этапом идёт разработка операционной модели для реализации инновационной стратегии. Процесс завершается внедрением разработанной операционной модели [2].

Важным аспектом в управлении инновациями является стимулирование студенческого предпринимательства. В ВУЗе, безусловно, существенно наделение студентов знаниями, умениями и навыками, которые они смогут применить для открытия бизнеса и коммерциализации своих разработок. Однако, опираясь лишь на теоретическую базу, студенты не будут развиваться как предприниматели. Отсутствие необходимых ресурсов и неуверенность в собственных только полученных знаниях при недостатке опыта отталкивают от открытия собственного дела.
Стимулировать развитие студенческого предпринимательства возможно путём проведения конкурсов на грантовую поддержку. Впрочем, большинство ВУЗов, в том числе и опорных в регионах, не имеют возможности осуществлять выплаты грантов. Существует вариант с привлечением спонсоров, которые будут полностью или частично финансировать выплаты. Зачастую в регионах многие даже крупные предприятия не охотно поддерживают такие инициативы.

Выходом в данной ситуации является сотрудничество с федеральными программами. Активно развивается в этом направлении Фонд содействия развитию малых форм предприятий в научно-технической сфере. Самый известный проект по поддержке студенческого препирательства в нём - программа «Умник». Участвуя в ней, появляется возможность получить грант в размере 500 тысяч рублей на 2 года на развитие инновационного проекта. Многие ВУЗы активно сотрудничают в рамках данной программы с фондом. Существенным для поддержания студенческих проектов является менторская поддержка преподавателей. Её возможно реализовать в рамках работы студенческих научных обществ.

Наиболее же эффективно менторская поддержка может раскрыться при внедрении акселерационных программ. Для реализации такого рода программ необходимо проведение регулярных встреч. Оптимальным выглядит периодичность в 1-2 раза в неделю при интенсивном развитии проектов. При меньшей интенсивности возможны встречи с большими промежутками, например, 1-2 раза в месяц. Как показывает практика, при меньшей периодичности акселерационная программа может стать неэффективной ввиду значительно медленного развития студенческих проектов.

Помимо регулярной работы с менторами-преподавателями возможно приглашение нерегулярных спикеров. Также важной особенностью может стать организация совета с нерегулярным членством, в рамках которого его члены будут оценивать реализацию и деятельность проектов в соответствии с контрольными точками. Ярким позитивным примером можно отметить MIT Global Founders' Skills Accelerator, начавший работу в 2012 году. В его рамках была разработана студенческая программа Beehive Cooperative [3]. Работа студенческой секции в 
нём оказалась менее продуктивной, но команды оказались более сплочёнными. Отмечается высокая интеграция этой программы в структуру работы университета.

Наиболее сложным вопросом в реализации работы акселератора для ВУЗа является привлечение экспертов, спикеров, менторов и специалистов, которые могут консультировать и контролировать стартапы. Вопрос финансирования здесь не маловажен. Основной упор возможно сделать на привлечение нерегулярных приглашённых экспертов, бывших выпускников ВУЗа, готовых поделиться опытом на безвозмездной основе. Опорные университеты в этом аспекте имеют больше преимуществ в плане своей репутации, а также количества и качества выпускников. Также привлечение возможно организовать через взаимодействие с местными и федеральными институтами развития. Это могут быть как уже упомянутый Фонд содействия развитию малых форм предприятий в научно-технической сфере, так и региональные, и федеральные организации, в частности, например, Фонд развития интернет-инициатив или Агентство стратегических инициатив.

Возможно открытие и бизнес-инкубаторов при ВУЗе, но это требует уже больших инвестиций. В частности, предполагается более серьёзное оборудование помещений. Бизнес-инкубатор в отличие от бизнес-акселератора предполагает обязательно организацию рабочих мест, а также может предоставлять консультационные, бухгалтерские и юридические услуги. Развитие бизнес-инкубаторов при опорных ВУЗах региона выглядит целесообразным ввиду потенциала обучающихся студентов, значительной материально-технической базой в сравнении с другим университетами региона, а также возможностей, раскрывающихся в синергетическом эффекте вышеперечисленных особенностей в совокупности с квалифицированной менторской поддержкой преподавателей.

Содержание бизнес-инкубатора финансово обосновано только при поддержке государства, частных инвесторов или его коммерциализации. Интерес студентов-предпринимателей будет не столь высоким, если их ВУЗ будет брать плату за возможность воспользоваться инфраструктурой. Поэтому для эффективного стимулирования развития инноваций в университете участие в бизнес-акселераторах и бизнес-инкубаторах для студентов опорных ВУЗов региона важно сделать бесплатным.

Также существенно сдвигать парадигму обучения. Уже сегодня современное обучение наравне с теорией даёт возможность получить практические навыки действия в реальных ситуациях. В частности, есть ряд примеров, в том числе и в России, когда стартап студента принимают в качестве выпускной квалификационной работы. Поистине практическую направленность можно получить благодаря фактической «упаковке» своей работы как стартапа. Каждую идею выпускной квалификационной работы необходимо приводить в максимальное соответствие к требованиям рынка или социальной направленности.

В процессе приведения своей идеи к коммерциализации или получению социального эффекта развиваются предпринимательские компетенции, которые помогают студентам если и не выходить на рынок со своими проектами, то хотя бы быстрее адаптироваться к современным реалиям. Однако здесь также, как и с обычными стартапами, важна менторская поддержка научных руководителей и, возможно, даже проведение своего рода demo days (в классическом понимании - презентация стартапа перед инвесторами, в данном случае же подразумевается презентация перед другими научными руководителями, студентами и при возможности приглашёнными экспертами для внесения конструктивных правок в проект). Однако данный процесс осуществим только при наличии иных составляющих инновационной инфраструктуры, описанных выше.

При управлении инновациями существенным выглядит тесное сотрудничество с различными организациями. Не все имеют возможность создавать корпоративные университеты. При этом зачастую у них ощущается серьёзная нехватка специалистов, которые способны работать в соответствии с новыми требованиями. Знания устаревают всё быстрее, обучение становится перманентным.

Так, например, в Липецкой области, в Пермском крае, в Республике Татарстан формируется и утверждается потребность экономики в кадрах. Координацию работы региональных центров по подготовке и переподготовке кадров могут взять на себя опорные ВУЗы регионов. Тесное сотрудничество с организациями будет способствовать к максимально быстрой адаптации университета к потребностям бизнеса [4]. 
Существенной проблемой становится, что опорный ВУЗ может выступить лишь с инициативой. Решение о формировании среднесрочных и долгосрочных прогнозов по подготовке сведений о потребности в рабочей силе производится в правительстве каждого региона. Создание региональных центров по подготовке и переподготовке кадров также происходит с участием правительства. Опорному ВУЗу при выходе с такой инициативой необходимо разработать концепцию деятельности в данном вопросе, максимально точно и полно проработать проект: разработать укрупнённый бюджет, представить схему взаимодействия участников, учесть уровень операционных доходов и расходов, выявив экономический и социальный эффект. Координированная работа с правительством позволит получить синергетический эффект в деятельности в отличие от работы самостоятельно в данном направлении.

Опорные ВУЗы регионов обладают огромным научным и техническим потенциалом. Многие из них имеют серьёзные научные разработки. Коммерциализировать научные разработки ВУЗы могут через создание малых инновационных предприятий. Получение прибыли становится важным аспектом при мотивации к развитию инновационных разработок, что также позволяет улучшать инновационную инфраструктуру.

Ключевым из факторов для коммерциализации результатов интеллектуальной деятельности является создание эффективной инфраструктуры и благоприятного инновационного климата в университете.

Первоначально результаты интеллектуальной деятельности необходимо поставить на бюджетный учёт. После чего проводится оценка права его использования, которая будет являться вкладом в уставной капитал. Необходимо также определиться с организационно-правовой формой предприятия, принять решение о создании хозяйственного общества или партнёрства, определиться с долей в уставном капитале. На заключительных этапах происходит регистрация в Федеральной налоговой службе, уведомление Министерства науки и высшего образования Российской Федерации о создании, а также заключение лицензионного договора с хозяйственным обществом или хозяйственным партнёрством.

Организация процесса создания малых ин- новационных предприятий в рамках деятельности ВУЗа является хоть и трудоёмкой, но достаточно привлекательной задачей. Опорные ВУЗы регионов имеют более существенную ресурсную и материально-техническую базу для их создания, чем региональные университеты без данного статуса. При этом прибыль, получаемая малыми инновационными предприятиями, предоставляет возможность к развитию материально-технической базы в виде лабораторий, производственных участков и т.д. Это будет способствовать увеличению рейтинга и конкурентоспособности ВУЗа, что привлечёт дополнительный поток абитуриентов. Также появляется возможность прохождения практики или трудоустройства студентов на базе малых инновационных предприятий.

В ВУЗе начинает формироваться инновационная среда, которая пронизывает весь процесс его деятельности. Для инноватора при этом культивируются благоприятные условия и окружение, в которых оказывается постоянная консультационная и, возможно, финансовая поддержка.

Данный факт способствует привлечению квалифицированных кадров в опорный ВУЗ, что, в свою очередь, улучшает качество образовательных программ и научно-исследовательской деятельности. В связи с этим также растёт рейтинг, конкурентоспособность и, как следствие, благополучие опорного ВУЗа.

При этом грамотное управление инновациями в опорных ВУЗах регионов должно строится всё также на главных столпах, которые приняты в коммерческих организациях. Либеральное отношение к ошибкам должно соседствовать с нетерпимостью к некомпетентности. Только квалифицированные сотрудники способны выдавать качественный продукт. При этом с уверенностью можно будет утверждать, что ошибки будут возникать из-за неопределённости, которая повсеместно сопровождает инновации, а не в связи с неспособностью сотрудника к выполнению данной деятельности.

Готовность к экспериментам должна соседствовать с дисциплиной. Важно тщательно планировать и правильно проводить эксперименты. Необходимо признавать неудачи, а не утверждать их корректность до самого конца.

Психологическая безопасность должна соседствовать с откровенностью. Существенно быть открытым и давать честную обратную 
связь в независимости от должности и ранга сотрудника.

Сотрудничество важно сочетать с ответственностью. При всей открытости и атмосфере взаимопомощи необходимо принимать личную ответственность, особенно это касается руководства.

Минимальное количество ступеней иерархии должно поддерживаться сильным лидерством. Плоская организационная структура без ответственного компетентного лидера погряз- нет в хаосе [5].

Перед опорными ВУЗами стоят серьёзные задачи, в числе которых модернизация образовательной, научно-исследовательской деятельности, развитие кадрового потенциала, материально-технической базы и социально-культурной инфраструктуры. Система управления инновациями университета способствует совершенствованию инновационной деятельности, которая содействует расширению возможностей опорных ВУЗов регионов.

\section{Библиографический список}

1. Инновации в России - неисчерпаемый источник роста [Электронный ресурс] / Центр по развитию инноваций McKinsey Innovation Practice, 2018. - 110 c. URL: https://www.mckinsey.com/ /media/McKinsey/Locations/ Europe\%20and\%20Middle\%20East/Russia/Our\%20Insights/Innovations\%20in\%20Russia/Innovations-in-Russia_ web_lq-1.ashx (дата обращения: 27.03.2019).

2. Управление инновациями в российских компаниях [Электронный ресурс] / PBK, iR\&Dclub, 2016. - 70 c. URL: https://www.rvc.ru/upload/iblock/0dd/Management_of_Innovations_in_Russian_Companies.pdf (дата обращения: 27.03.2019).

3. Официальный сайт MIT Global Startup Labs [Электронный ресурс]. URL: http://gsl.mit.edu/ (дата обращения: 27.03.2019).

4. Региональный стандарт Агентства стратегических инициатив [Электронный ресурc]. URL: https://asi.ru/ investclimate/standard/ (дата обращения: 27.03.2019).

5. Гэри П. Пизано. Горькая правда о культуре инноваций [Электронный ресурс] / Harvard business review, 2019. URL: https://hbr-russia.ru/innovatsii/upravlenie-innovatsiyami/794907 (дата обращения: 27.03.2019). 